\title{
Correction to: When are committees of Condorcet winners Condorcet winning committees?
}

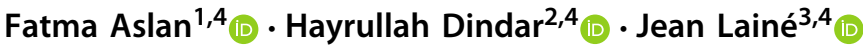

๑) Springer-Verlag GmbH Germany, part of Springer Nature 2021

\section{Correction to: Review of Economic Design https://doi.org/10.1007/s10058-021-00260-9}

In this article the affiliation details for Author Jean Lainé were incorrectly given as 'Lirsa, National des Arts et Métiers, Paris, France' but should have been "Lirsa, Conservatoire National des Arts et Métiers, Paris, France"

In this article, the equation $\boldsymbol{\beta}$ should be changed to $\pi$

The original article has been corrected.

Publisher's Note Springer Nature remains neutral with regard to jurisdictional claims in published maps and institutional affiliations.

The original article can be found online at https://doi.org/10.1007/s10058-021-00260-9.

$凶 \quad$ Jean Lainé

jean.laine@lecnam.net

Fatma Aslan

aslan.fatma@gtk.bme.hu

Hayrullah Dindar

hayrullah.dindar@bilgi.edu.tr

1 Quantitative Social and Management Sciences Research Centre, Faculty of Economic and Social Sciences, Budapest University of Technology and Economics, Budapest, Hungary

2 Economics Department, Istanbul Bilgi University, Istanbul, Turkey

3 Lirsa, Conservatoire National des Arts et Métiers, Paris, France

4 Murat Sertel Center for Advanced Economic Studies, Istanbul Bilgi University, Istanbul, Turkey 